\title{
Head and neck cancer relapse after chemoradiotherapy correlates with CD163 + macrophages in primary tumour and CD11b + myeloid cells in recurrences
}

P Balermpas ${ }^{1}$, F Rödel ${ }^{1}$, R Liberz ${ }^{2}$, J Oppermann ${ }^{1}$, J Wagenblast ${ }^{3}$, S Ghanaati ${ }^{4}, \mathrm{P}$ N Harter ${ }^{5}, \mathrm{M}$ Mittelbronn ${ }^{5}$, C Weiss ${ }^{1}$, C Rödel ${ }^{1,6}$ and E Fokas ${ }^{*}, 1$

${ }^{1}$ Department of Radiation Therapy and Oncology, Johann Wolfgang Goethe University, Frankfurt, Germany; ${ }^{2}$ Senckenberg Institute of Pathology, Goethe University, Frankfurt, Germany; ${ }^{3}$ Department of Head and Neck Surgery, Goethe University, Frankfurt, Germany; ${ }^{4}$ Department of Maxillofacial Surgery, Goethe University, Frankfurt, Germany; ${ }^{5}$ Edinger Institute, Institute of Neurology, Goethe University, Frankfurt, Germany and ${ }^{6}$ German Cancer Consortium (DKTK), Partner Site Frankfurt and German Cancer Research Center (DKFZ), Heidelberg, Germany

Background: We investigated the prognostic role of tumour-associated macrophages (TAMs) in patients with head and neck squamous cell carcinoma (HNSCC) treated with definitive chemoradiotherapy (CRT).

Methods: The expression of CD68+, CD163 + and CD11b + cells was assessed using immunohistochemistry in $n=106$ pre-treatment tumour biopsy samples and was correlated with clinicopathological characteristics, including T-stage, N-stage, grading, tumour localisation, age and sex as well as local failure-free survival (LFFS), distant metastases-free survival (DMFS), progression-free (PFS), and overall survival (OS). Finally, TAMs expression and vessel density (CD31) were examined in $n=12$ available early local recurrence samples and compared with their matched primary tumours. The diagnostic images and radiotherapy plans of these 12 patients were also analysed. All local recurrences occurred in the high radiation dose region ( $\geqslant 70$ Gy).

Results: With a median follow-up of 40 months, OS at 2 years was $60.5 \%$. High CD163 expression in primary tumours was associated with decreased OS $(P=0.010)$, PFS $(P=0.033)$, LFFS $(P=0.036)$ and DMFS $(P=0.038)$ in multivariate analysis. CD163 demonstrated a strong prognostic value only in human papillomavirus $\left(\mathrm{p} 16^{\text {INK4 }}\right)$-negative patients. Early local recurrence specimens demonstrated a significantly increased infiltration of CD11b + myeloid cells $(P=0.0097)$ but decreased CD31-positive vessel density $(P=0.0004)$ compared with their matched primary samples.

Conclusions: Altogether, baseline CD163 expression predicts for an unfavourable clinical outcome in HNSCC after definitive CRT. Early local recurrences showed increased infiltration by CD11b + cells. These data provide important insight on the role of TAMs in mediating response to CRT in patients with HNSCC.

Head and neck squamous cell carcinoma (HNSCC) is the sixth most common malignancy in the world (Argiris et al, 2008). Despite significant advances in treatment modalities, such as surgery and chemoradiotherapy (CRT), local and distant recurrence is encountered in $\sim 30 \%$ of the cases (Argiris et al, 2008). Hence, there is an imperative need to identify novel biological markers that predict patients at high risk of disease recurrence. 
HNSCC has been associated with a variety of aetiological agents, such as alcohol consumption, tobacco use and human papillomavirus (HPV) infection. Approximately $20-25 \%$ of patients are HPV-positive, most prominently subtype 16 (Chaturvedi et al, 2011). HPV-positive patients present better response to RT/CRT and are characterised by a more favourable prognosis compared with HPV-negative patients (Ang et al, 2010). Immunohistochemical detection of the cell cycle regulatory protein $\mathrm{p} 16^{\mathrm{INK} 4 \mathrm{a}}$ has been commonly used to validate HPV infection (Lassen et al, 2009).

Immune-regulated pathways influence several aspects of malignant development, and cancers present a highly immunosuppressive microenvironment that promotes tumour progression (Bhardwaj, 2007). In that context, tumor-associated macrophages (TAMs) have been identified as key regulators of tumour immunosuppression, angiogenesis, migration, metastasis and treatment evasion (Qian and Pollard, 2010; De Palma and Lewis, 2013). Macrophages can be polarised towards either M1 or M2 macrophages. M1 macrophages activate type 1 helper T cells (Th1) and foster the immune response against pathogens or malignant cells, whereas M2 macrophages lead to an anti-inflammatory response that promotes tumour cell growth and metastasis (Qian and Pollard, 2010; De Palma and Lewis, 2013). In a similar fashion, myeloid-derived suppressor cells, such as CD11b + myeloid cells, mediate tumour immunosuppression, restoration of tumour vasculature and refractoriness to RT (Gabrilovich and Nagaraj, 2009; De Palma and Lewis, 2013).

TAMs have been associated with poor prognosis in glioma, lymphoma, melanoma, sarcomas, breast and lung cancer (Lee et al, 2008; Jensen et al, 2009; Steidl et al, 2010; Chung et al, 2012; Medrek et al, 2012; Tan et al, 2012; Lima et al, 2013; Pyonteck et al, 2013). CD68 has been commonly used as a macrophage marker for immunohistochemistry but is essentially a pan-macrophage marker that is unspecific to the monocyte/macrophage lineage. CD163 is a transmembrane scavenger receptor for haptoglobinhemoglobin complexes that is predominantly regarded as a specific monocyte/macrophage marker for M2 macrophages (Lau et al, 2004; Qian and Pollard, 2010; Ambarus et al, 2012).

Although previous reports have examined the role of TAMs in HNSCC, the majority of the studies included patients treated with surgery (Li et al, 2002; Marcus et al, 2004; Mori et al, 2011; Fujii et al, 2012), whereas the prognostic value of TAMs in patients treated with definitive CRT remains unknown. Similarly, the impact of CD11b + myeloid cells in patients with HNSCC has not been explored. In the present study, we examined the prognostic value of CD68, CD163 and CD11b in pretherapeutic core biopsy samples from 106 patients treated homogeneously with definitive CRT. Biopsies from $n=12$ early local tumour recurrences were available, and hence we also assessed TAMs and blood vessel density in those 12 samples and compared expression with their matched primary tumours. Finally, the prognostic significance of TAMs according to the surrogate marker p16 ${ }^{\mathrm{INK} 4 \mathrm{a}}$ (HPV16) status was investigated.

\section{PATIENTS AND METHODS}

Patients. Between 2007 and 2011, a total of 106 patients with histologically confirmed locally advanced HNSCC received definitive CRT at the Department of Radiotherapy and Oncology, University Hospital Frankfurt am Main, Germany. Tumour diagnosis and staging were based on physical examination, baseline tumour biopsy, CT/MRI of head and neck and chest/abdomen, chest X-ray and full blood count. Tumour staging was performed in accordance with the Union International Contre le Cancer (UICC) and the American Joint Committee on Cancer. Inclusion criteria were as follows: histopathological diagnosis of HNSCC; age $\geqslant 18$ years; good blood, liver and renal function; lack of metastasis and/or second cancer; curative intent. Ethical approval for the present study was obtained from the local ethics committee of Goethe University Frakfurt, Germany.

Treatment protocol and follow-up. Treatment was applied using either a 3D-based RT or intensity-modulated RT and immobilisation with thermoplastic masks. CT and MRI scans were used for target volume delineation. A prophylactic feeding tube was inserted before commencing CRT. The latter was administered using $\geqslant 6 \mathrm{MeV}$ energy photon beams once daily with standard fractionation of 1.8-2 Gy to a total dose of 70-72 Gy. During the second half of the RT (following 15 fractions of $2 \mathrm{~Gy}$ to a dose of $30 \mathrm{~Gy}$ ), a hyperfractionated accelerated fractionation schedule (1.4-1.5 Gy twice daily) was used as described (Budach et al, 2005). Four patients received a different RT fractionation schedule. Chemotherapy consisted of 5 -FU $\left(600 \mathrm{mg} \mathrm{m}^{-2}\right.$ per day) as a continuous 120 -h intravenous infusion and Cisplatin $\left(20 \mathrm{mg} \mathrm{m}^{-2}\right.$ per day) as short intravenous infusion, both administered on days 1-5 and 29-33 of RT. Patients with poor kidney function ( $<60 \mathrm{ml} \mathrm{h}^{-1}$ creatinine clearance) instead received carboplatin or mitomycin-C. A reduction in chemotherapy dose was considered in case of leukopenia (leucocyte count $<3 \mathrm{nl}^{-1}$ ) and/ or thrombocytopenia (platelet count $<100000 \mathrm{nl}^{-1}$ ). Definitive CRT was applied following presentation of the case to the weekly Head and Neck Cancer multidisciplinary tumour board in the following cases: $(1) \geqslant \mathrm{T} 3$-stage; (2) patients with poor general health status who were considered inoperable; and (3) patients who have electively opted for CRT.

Follow-up was performed 6 weeks upon completion of CRT and thereafter at 3-month intervals and included clinical examination with endoscopy and CT/MRI imaging. Patients with suspicious clinical and radiologic findings received a biopsy. Patient characteristics are shown in Supplementary Table 1.

Immunohistochemical evaluation of CD68, CD163, CD11b, p16 ${ }^{\text {INK4a }}$ and CD31. Formalin-fixed, paraffin-embedded blocks from pre-treatment tumour biopsies and tumour recurrences were provided by the Institute for Pathology, University Hospital Frankfurt archives. Immunohistochemical detection of CD68, CD163 and CD11b were performed with a horseradish-peroxidase technique using a DAKO Autostainer Link 48 (DAKO, Hamburg, Germany). Antigens were retrieved following pre-treatment of microscope slides (Star Frost, Engelbrecht, Germany) with an Epitope Retrieval Solution (Trilog, Cell Marque, Rocklin, CA, USA) for $30 \mathrm{~min}$. A standardised Dako EnVision FLEX Peroxidase Blocking reagent (K800, DAKO) and mouse monoclonal antibodies for CD68 (IS609, DAKO), CD163 (dilution 1:100, Cell Marque), and rabbit polyconal CD11b (dilution 1:100, Novus Biologicals, Littleton, CO, USA) were used for immunostaining following incubation for $20 \mathrm{~min}$ at room temperature. Visualisation was performed using a dextran polymer-conjugated horseradishperoxidase and 3,3'-diaminobenzidine chromogen followed by counterstaining with hematoxylin solution (Gill 3, Sigma Aldrich, Munich, Germany). For each staining, negative control slides (absent primary antibody) were included as well. Immunohistochemical staining of $\mathrm{p} 16^{\mathrm{INK} 4 \mathrm{a}}$ protein (HPV16) has been previously described (Balermpas et al, 2014). CD31 immunohistochemistry was performed using a mouse anti-human CD31 antibody diluted 1:200 (clone JC70A Dako, Glostrup, Denmark) and the Discovery $\mathrm{XT}$ automated IHC system (Ventana, Tucson, Arizona) as we reported before (Baumgarten et al, 2014).

Immunohistochemistry scoring. We performed a semi-quantitative scoring of TAMs by measuring the density of CD68+, CD163 + and also of myeloid CD11b + cells as follows:(1) no, or sporadic cells; (2) moderate numbers of cells; (3) abundant occurrence of cells; and (4) highly abundant occurrence of cells. 
We evaluated TAMs in three different tumour compartments: the intraepithelial compartment, the stroma, and the tumour periphery in three random fields $(\times 10$ magnification). Necrotic areas were excluded from the analysis. The total score of CD68, CD163 and $\mathrm{CD} 11 \mathrm{~b}$ immunostaining was calculated as the sum of the individual scores from the three tumour compartments (intraepithelial compartment, stroma and tumour periphery), respectively. The total score ranged from 3 to 12 . We used the median value as a cutoff value to separate the patient cohort into two groups with either low or high CD68, CD163 and CD11b expression.

We also evaluated the prognostic significance of the TAMs score for each of the three different tumour compartments (intraepithelial compartment, stroma and tumour periphery) separately. For that purpose, we calculated the median TAMs score of each area and the cutoff point was used to separate the cohort into two groups with either low or high TAMs score. To validate the semiquantitative scoring of TAMs expression, the number of cells was measured in three randomised $\times 10$ magnification fields per sample. Following that, the median cell number was used as a cutoff point to separate the patient cohort into two groups with either low or high TAMs cell number.

Additionally, the prognostic value of HPV16 based on the HPV16 immunoreactivity (positive $v s$ negative) was investigated. The prognostic value of TAMs was assessed separately in HPV16positive and HPV16-negative patients.

Biopsy material of early local recurrences from the high radiation dose area was available in $n=12$ patients. Hence, we assessed TAMs expression in those 12 patients and their median cell number was compared with their matched primary tumours ( $\times 10$ magnification field; 3-4 images per tumor). Primary tumours and matched recurrent samples were also stained with hematoxylin and eosin (H\&E) as previously described (Fokas et al, 2012b). CD31-based blood vessel density in the $n=12$ recurrent tumours and their matched samples was assessed as reported (Baumgarten et al, 2014).

To minimise interobserver variability, scoring was performed by two independent investigators (PB and $\mathrm{EF}$ ) without knowledge of the clinicopathological data. In case of discrepancy, a consensus was drawn following re-examination of the slides at the microscope. Images were acquired using an AxioImager $\mathrm{Z} 1$ microscope, equipped with an Axiocam camera and Axiovision 4.6 software (Zeiss, Göttingen, Germany).

Examination of diagnostic images and RT plans in recurrent tumours. To determine the area of local recurrence, we examined the diagnostic images (CT and MRI) and initial radiotherapy plans of the 12 patients. The recurrent tumour was contoured using the Oncentra Masterplan planning software (Nucletron, Veenendaal, The Netherland) and co-registered with the initial planning computed tomography scan of the primary tumour to assess the pattern of local failure after CRT.

Statistical analysis. The Fisher's exact test was used to assess the differences between categorical variables. Overall survival (OS) and time to recurrence were measured from the start of CRT diagnosis to the day of death and recurrences, respectively. Patients without tumour recurrence were censored at the last follow-up contact. Progression-free survival (PFS) was defined as the time between the beginning of CRT diagnosis and tumour relapse (locoregional recurrence and/or distant metastases) or death owing to tumorunrelated causes. Local failure-free survival (LFFS) was calculated from the beginning of CRT to the first local tumour detection after CRT (i.e. non-complete response), local tumour recurrence after complete response or death from any cause. Distant metastasesfree survival (DMFS) was assessed separately. Significance was defined as a $P<0.05$. Survival curves were plotted by using the Kaplan-Meier method. Univariate and multivariate analysis were performed using the log-rank (Mantel-Cox) test and the Cox proportional hazard models, respectively. Statistical analyses were performed using the SPSS Version 19 statistical programme (version 15.0, IBM, Amonk, NY, USA) and the Graphpad Prism version 4.0 (GraphPad Software, La Jolla, CA, USA).

\section{RESULTS}

TAMs expression in primary tumours and correlation with clinicopathologic parameters. Table 1 shows the immunohistochemistry characteristics and labelling scores for CD68, CD163 and CD11b, based on the median cutoff value of immunohistochemistry score. With regard to TAMs correlation to clinicopathological parameters, (Table 2), a significantly higher incidence of N2-3 stage that is, advanced lymphadenopathy was found in patients with higher CD68 expression (97.2\%) compared with patients with low CD68 expression (80\%). Interestingly, the incidence of $\mathrm{cN} 2 \mathrm{c}-3$ stage was higher in patients with low CD68 expression, which is likely cohort related. Also, 20\% of patients with low CD68 expression presented cN0-1 stage compared with only $2.8 \%$ in those with high CD68 expression, indicating a more aggressive disease phenotype $(P=0.003)$. We failed to identify any other significant relationship between TAMs expression and clinicopathologic parameters (Table 2).

TAMs in primary tumours and correlation with clinical outcome. After a median follow-up of 40 months (range, 2.3-72 months), OS at 2 years was $60.5 \%$ for the entire cohort. In univariate analysis, patients with high CD68 expression had a significantly worse OS (low vs high CD68: mean 48.0 vs 31.9 months; $P=0.017$ ), PFS (low vs high CD68: mean 43.5 vs 27.6 months; $P=0.010$ ), LFFS (low vs high CD68: mean 44.0 vs 28.0 months; $P=0.006$ ) and DMFS (low vs high CD68: mean 46.6 vs 30.8 months; $P=0.011$ ) (Figure 1A and Table 3). Similarly, high CD163 expression was associated with unfavourable outcome. Indeed, patients with low CD163 expression presented a better OS (low vs high CD163: mean 48.7 vs 34.1 months; $P=0.007$ ), PFS (low vs high CD163: mean 45.3 vs 28.3 months; $P=0.006$ ), LFFS (low vs high CD163: mean 45.6 vs 29.0 months; $P=0.007$ ) and DMFS (low vs high CD163: mean 48.0 vs 32.1 months; $P=0.010$ ) (Figure $1 \mathrm{~B}$ and Table 3 ). CD11b expression did not affect outcome in univariate analysis. Of note, univariate analysis failed to detect a statistical significance for the clinicopathological parameters with regard to the clinical end points (Table 3 ). In the Cox model (multivariate analysis), only high CD163 expression was confirmed as an independent prognostic parameter for worse OS $(P=0.010)$, PFS $(P=0.033)$, LFFS $(P=0.036)$ and DMFS $(P=0.038)$ (Table 3$)$.

Importantly, we validated the semi-quantitative scoring of TAMs expression by measuring the median number of cells per tumour field ( $\times 10$ magnification) and confirmed the prognostic value of CD68 and CD163 for all four clinical end points (Supplementary Table 2; Supplementary Figure 1).

\begin{tabular}{|c|c|c|c|}
\hline Marker & $\begin{array}{c}\text { CD68 } N \\
(\%)\end{array}$ & $\begin{array}{c}\text { CD163 N } \\
(\%)\end{array}$ & $\begin{array}{l}\text { CD11b N } \\
\text { (\%) }\end{array}$ \\
\hline Dichotomised labelling score ${ }^{a}$ & $\leqslant 4$ vs $>4$ & $\leqslant 4$ vs $>4$ & $\leqslant 5 v s>5$ \\
\hline Low score & $70(66.0)$ & $59(55.7)$ & $63(59.4)$ \\
\hline High Score & $36(34.0)$ & $47(44.3)$ & $43(40.6)$ \\
\hline \multicolumn{4}{|c|}{$\begin{array}{l}\text { a Dichotomised labelling (low vs high score) was based on the median value of marker's } \\
\text { expression. }\end{array}$} \\
\hline
\end{tabular}


Table 2. Patient and treatment characteristics

\begin{tabular}{|c|c|c|c|c|c|c|c|c|c|}
\hline & $\begin{array}{l}\text { Low } \\
\text { CD68 }\end{array}$ & $\begin{array}{l}\text { High } \\
\text { CD68 }\end{array}$ & & $\begin{array}{c}\text { Low } \\
\text { CD163 }\end{array}$ & $\begin{array}{l}\text { High } \\
\text { CD163 }\end{array}$ & & $\begin{array}{l}\text { Low } \\
\text { CD11b }\end{array}$ & $\begin{array}{c}\text { High } \\
\text { CD11b }\end{array}$ & \\
\hline & $n(\%)$ & $n(\%)$ & $P$-value & $n(\%)$ & $n(\%)$ & $P$-value & $n(\%)$ & $n(\%)$ & $P$-value \\
\hline \multicolumn{10}{|l|}{ Age } \\
\hline $\begin{array}{l}<60.6 \text { years } \\
\geqslant 60.6 \text { years }\end{array}$ & $\begin{array}{l}37(52.9 \%) \\
33(47.1 \%)\end{array}$ & $\begin{array}{l}16(44.4 \%) \\
20(55.6 \%)\end{array}$ & 0.269 & $\begin{array}{l}30(50.8 \%) \\
29(49.2 \%)\end{array}$ & $\begin{array}{l}23(48.9 \%) \\
24(51.1 \%)\end{array}$ & 0.500 & $\begin{array}{l}28(44.4 \%) \\
35(55.6 \%)\end{array}$ & $\begin{array}{l}25(58.1 \%) \\
18(41.9 \%)\end{array}$ & 0.118 \\
\hline \multicolumn{10}{|l|}{ Gender } \\
\hline $\begin{array}{l}\text { Male } \\
\text { Female }\end{array}$ & $\begin{array}{l}55(65.5 \%) \\
29(34.5 \%)\end{array}$ & $\begin{array}{r}15(68.2 \%) \\
7(31.8 \%)\end{array}$ & 0.512 & $\begin{array}{l}47(79.7 \%) \\
12(20.3 \%)\end{array}$ & $\begin{array}{l}37(78.7 \%) \\
10(21.2 \%)\end{array}$ & 0.547 & $\begin{array}{l}51(81 \%) \\
12(19 \%)\end{array}$ & $\begin{array}{l}33(76.7 \%) \\
10(23.3 \%)\end{array}$ & 0.387 \\
\hline \multicolumn{10}{|c|}{ Fractionation mode } \\
\hline $\begin{array}{l}\text { Normofractionated } \\
\text { HART } \\
\text { Completely hyperfr. } \\
\text { SIB } \\
\text { Other }\end{array}$ & $\begin{array}{c}55(78.6 \%) \\
13(18.6 \%) \\
1(1.4 \%) \\
0(0 \%) \\
1(1.4 \%)\end{array}$ & $\begin{array}{c}26(72.2) \\
8(22.2 \%) \\
0(0 \%) \\
1(2.8 \%) \\
1(2.8 \%)\end{array}$ & 0.562 & $\begin{array}{l}46(78 \%) \\
10(16.9 \%) \\
0(0 \%) \\
1(1.7 \%) \\
2(3.4 \%)\end{array}$ & $\begin{array}{c}35 \text { (74.5\%) } \\
11(23.4 \%) \\
1(2.1 \%) \\
0(0 \%) \\
0(0 \%)\end{array}$ & 0.375 & $\begin{array}{l}47(74.6 \%) \\
14(22.2 \%) \\
0(0 \%) \\
0(0 \%) \\
2(3.2 \%)\end{array}$ & $\begin{aligned} 34 & (79.1 \%) \\
7 & (16.3 \%) \\
1 & (2.3 \%) \\
1 & (2.3 \%) \\
0 & (0 \%)\end{aligned}$ & 0.307 \\
\hline \multicolumn{10}{|l|}{ Tumour site } \\
\hline $\begin{array}{l}\text { Oral cavity } \\
\text { Oropharynx } \\
\text { Hypopharynx } \\
\text { Larynx } \\
\text { Other }\end{array}$ & $\begin{array}{l}17(24.3 \%) \\
33(47.1 \%) \\
17(24.3 \%) \\
3(4.3 \%) \\
0(0 \%)\end{array}$ & $\begin{array}{c}10(27.8 \%) \\
12(33.3 \%) \\
10(27.8 \%) \\
2(5.6 \%) \\
2(5.6 \%)\end{array}$ & 0.384 & $\begin{array}{l}13(22 \%) \\
25(42.4 \%) \\
18(30.5 \%) \\
3(5.1 \%) \\
1(1.7 \%)\end{array}$ & $\begin{array}{c}14(29.8 \%) \\
20(42.6 \%) \\
9(19.1 \%) \\
3(6.4 \%) \\
1(2.1 \%)\end{array}$ & 0.384 & $\begin{array}{c}17(27 \%) \\
27(42.9 \%) \\
15(23.8 \%) \\
3(4.8 \%) \\
1(1.6 \%)\end{array}$ & $\begin{array}{c}10(23.3 \%) \\
18(41.9 \%) \\
12(27.9 \%) \\
2(4.7 \%) \\
1(2.3 \%)\end{array}$ & 0.782 \\
\hline \multicolumn{10}{|l|}{ T-staging } \\
\hline $\begin{array}{l}\text { cT1-2 } \\
\text { cT3-4 }\end{array}$ & $\begin{array}{r}7(10 \%) \\
63(90 \%)\end{array}$ & $\begin{array}{c}3(8.3 \%) \\
33(91.7 \%)\end{array}$ & 0.541 & $\begin{array}{c}4 \text { (6.8\%) } \\
55 \text { (93.2\%) }\end{array}$ & $\begin{array}{r}6(12.8 \%) \\
41(87.2 \%)\end{array}$ & 0.237 & $\begin{array}{c}6(9.5 \%) \\
57(90.5 \%)\end{array}$ & $\begin{array}{c}4(9.3 \%) \\
39 \text { (90.7\%) }\end{array}$ & 0.623 \\
\hline \multicolumn{10}{|l|}{$\mathrm{N}$-staging } \\
\hline $\begin{array}{l}\text { cN0-1 } \\
\text { cN2a-2b } \\
\text { cN2c-3 }\end{array}$ & $\begin{array}{l}14(20 \%) \\
18(25.7 \%) \\
38(54.3 \%)\end{array}$ & $\begin{array}{c}1 \text { (2.8\%) } \\
20(55.6 \%) \\
15(41.7 \%)\end{array}$ & 0.003 & $\begin{array}{l}12(20.3 \%) \\
19(32.2 \%) \\
28(47.5 \%)\end{array}$ & $\begin{array}{c}3 \text { (6.4\%) } \\
19(40.4 \%) \\
25(53.2 \%)\end{array}$ & 0.118 & $\begin{array}{r}7(11.1 \%) \\
23(36.5 \%) \\
33(52.4 \%)\end{array}$ & $\begin{array}{r}8(18.6 \%) \\
15(34.9 \%) \\
20(46.5 \%)\end{array}$ & 0.546 \\
\hline \multicolumn{10}{|l|}{ Grading } \\
\hline $\begin{array}{l}\text { G1 } \\
\text { G2 } \\
\text { G3 }\end{array}$ & $\begin{array}{c}4 \text { (5.7\%) } \\
55 \text { (78.6\%) } \\
11(15.7)\end{array}$ & $\begin{array}{c}1 \text { (2.8\%) } \\
27 \text { (75\%) } \\
8(22.2 \%)\end{array}$ & 0.596 & $\begin{array}{c}4 \text { (6.8\%) } \\
44 \text { (74.6\%) } \\
11(18.6 \%)\end{array}$ & $\begin{array}{c}1 \text { (2.1\%) } \\
38 \text { (80.9\%) } \\
8(17 \%)\end{array}$ & 0.504 & $\begin{array}{c}1(1.6 \%) \\
52(82.5 \%) \\
10(15.9 \%)\end{array}$ & $\begin{array}{c}4(9.3 \%) \\
30(69.8 \%) \\
9(20.9 \%)\end{array}$ & 0.127 \\
\hline \multicolumn{10}{|l|}{ Smoking history } \\
\hline $\begin{array}{l}\text { Yes } \\
\text { No }\end{array}$ & $\begin{array}{l}37 \text { (62.7\%) } \\
22(37.3 \%)\end{array}$ & $\begin{array}{l}22 \text { (46.8\%) } \\
25 \text { (53.2\%) }\end{array}$ & 0.164 & $\begin{array}{l}33 \text { (61.1\%) } \\
21 \text { (38.9\%) }\end{array}$ & $\begin{array}{l}25(49 \%) \\
26(51 \%)\end{array}$ & 0.133 & $\begin{array}{l}29(46 \%) \\
34(54 \%)\end{array}$ & $\begin{array}{l}28 \text { (54.9\%) } \\
23 \text { (45.1\%) }\end{array}$ & 0.176 \\
\hline
\end{tabular}

Additionally, we examined the prognostic value of TAMs expression, based on the three different tumour compartments (intraepithelial, tumour stroma and tumour periphery; Supplementary Table 3; Supplementary Figure 2A and B). Interestingly, we observed differences in prognostic significance of TAMs that was dependent on the tumour compartment. Indeed, high expression of CD68 in tumour stroma was significantly associated with worse OS $(P=0.010)$, PFS $(P=0.009)$, LFFS $(P=0.004)$ and DMFS $(P=0.012)$, whereas differences in CD68 expression in intraepithelial compartment and periphery did not have a prognostic impact. Similarly to CD68, low CD163 expression in tumour stroma was associated with superior OS $(P=0.006)$, PFS $(P=0.001)$ and LFFS $(P=0.001)$ and DMFS $(P=0.003)$, whereas CD163 expression in tumour cell and periphery did not affect outcome. CD11b analysis in the different tumour compartments did not show significance for any of the clinical end points (Supplementary Table 3). Representative examples of tumours with low and high stromal CD68 and CD163 expression are shown in Figure 2.

TAMs in recurrent tumours. Furthermore, we examined the expression of TAMs in available biopsy samples from 12 patients that developed early local recurrence and compared it with their matched primary tumour samples (Figures $3 \mathrm{~A}-\mathrm{C}$ ). We failed to detect a significant difference in $\mathrm{CD} 68+$ and $\mathrm{CD} 163+$ cell numbers between the early recurrence and their matched primary tumour biopsy samples. In contrast, examination of the recurrence samples in 10 of the 12 patients with early recurrence demonstrated a significant increase in the number of CD11b + cells $(P=0.0097)$ compared with their matched primary samples. Recurrent tumours showed significantly lower vascular density $(P=0.0004)$ compared with their matched primary samples 

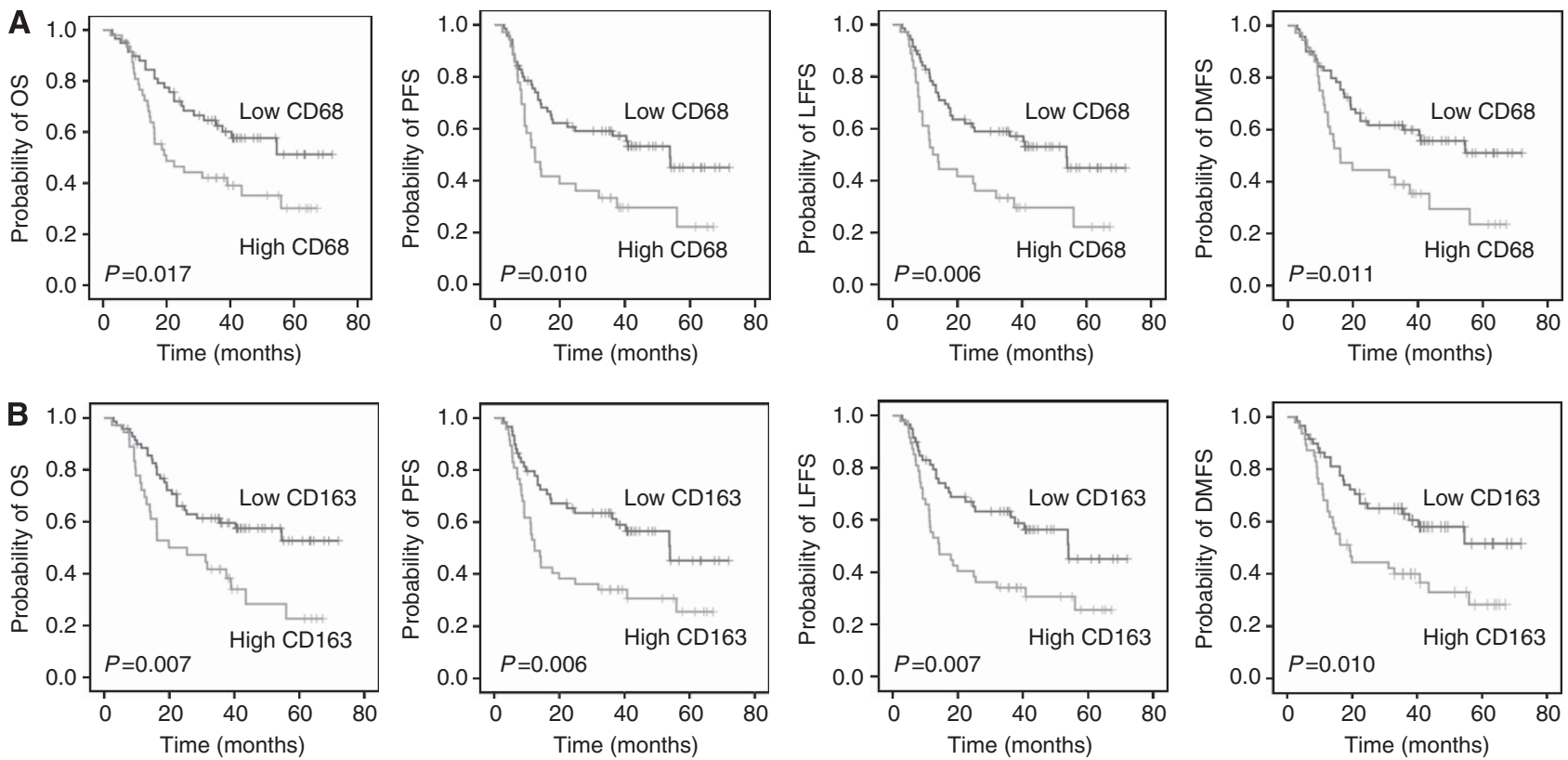

Figure 1. Prognostic significance of the TAMs markers (A) CD68 and (B) CD163 with regard to overall survival (OS), progression-free survival (PFS), locoregional failure-free survival (LFFS) and distant metastases-free survival (DMFS) in patients with head and neck cancer following definitive chemoradiotherapy.

(Supplementary Figure 3A). H\&E staining of the primary tumours demonstrated increased fibrosis in recurrent tumours, which is expected owing to previous CRT (Supplementary Figure 3B).

Assessment of the diagnostic images and RT plans showed that in all 12 patients local recurrences occurred in the high radiation dose area, located within the $95 \%$ isodose of the prescribed dose of $\geqslant 70$ Gy (Supplementary Figure 3C).

TAMs in correlation with HPV16 status. Finally, we analysed the prognostic value of HPV16 alone as well as in correlation with CD163 that showed significance in multivariate analysis and CD11b (Supplementary Tables 4 and 5; Supplementary Figure 4A and B). HPV16 status in primary tumours did not predict for clinical outcome. CD163 in primary tumours presented a strong prognostic value only in HPV-negative patients (PFS: $P=0.024$; LFFS: $P=0.028$; and DMFS: $P=0.045)$, except for OS $(P=0.077)$. Again, CD11b did not affect any of the four clinical end points in correlation to HPV16. Images of tumours with positive and negative HPV16 expression are shown in Supplementary Figure 4B.

\section{DISCUSSION}

In the present work, patients with high expression of CD163+ TAMs in their primary tumours presented significantly worse clinical outcome compared with patients with low infiltration by TAMs. This observation was independent of clinicopathological factors with a predictive role in this disease.

In line to our findings, several studies have shown a protumorigenic role for TAMs (De Palma and Lewis, 2013) and demonstrated a significant association between high levels of TAMs and unfavourable prognosis in patients with various malignancies (Lee et al, 2008; Jensen et al, 2009; Steidl et al, 2010; Chung et al, 2012; Medrek et al, 2012; Tan et al, 2012; Lima et al, 2013; Pyonteck et al, 2013). However, immunohistochemical analysis in most of these studies was restricted to CD68, a panmacrophage marker that recognises both tumoricidal (M1) and anti-inflammatory pro-tumorigenic (M2) macrophages, whereas only few have incorporated the use of an M2-specific TAMs marker, such as CD163 (Lau et al, 2004; Qian and Pollard, 2010; Ambarus et al, 2012). Here, we included the assessment of an antibody against CD163 to identify these TAMs.

With regard to HNSCC, only few reports on the prognostic relevance of TAMs have been published so far. The majority of these studies included patients treated with surgery that did not analyse the impact of TAMs on survival (Kerrebijn et al, 1994). Li et al (2002), Mori et al (2011) and Marcus et al (2004) showed that TAMs were associated with advanced stage and higher pathological grade in surgically treated patients with oral cancer Russell et al (2013) failed to detect a prognostic value for CD68 + TAMs after studying immune cell infiltration patterns in 33 patients treated by surgery. In 108 patients with HNSCC who received surgical resection, CD163 was correlated with worse OS (Fujii et al, 2012), as in our work. However, even though 62 of these patients presented with advanced disease (Stage III-IV), they did not receive adjuvant treatment and the tumour resection status (R0- vs R1/R2-resection) was not reported that makes interpretation of these findings challenging. In contrast to the above mentioned studies, an important strength of our work relies on the fact that it includes a large cohort of patients $(n=106)$ treated homogeneously with definitive CRT in a single institution.

We observed differences in the prognostic value of CD68 + and CD163 + TAMs that varied according to the tumour compartment. High CD68 + and CD163 expression in tumour stroma was associated with worse prognosis, whereas TAMs infiltration in the intraepithelial compartment or tumour periphery did not affect outcome. The tumour microenvironment is characterised by the accumulation of different host-derived stroma cells, such as TAMs. Indeed, TAMs are a major component of tumour stroma. The interaction between tumour cells and stromal TAMs aggravates the inflammatory response, leading to tumour progression (De Palma and Lewis, 2013). Additionally, accumulating evidence suggests targeting the stromal TAMs as an effective anticancer therapy (Ibe et al, 2001; Luo et al, 2006). These data support our findings regarding the predictive role of TAMs in the stromal compartment in our series. To the best of our knowledge, the present study is the first to examine in detail the prognostic significance of TAMs in 
Table 3. Univariate and multivariate analyses of prognostic factors in patients with HNSCC

\begin{tabular}{|c|c|c|c|c|c|}
\hline & \multirow{2}{*}{$\begin{array}{c}\text { Univariate } \\
P \text {-value }\end{array}$} & \multirow[b]{2}{*}{ HR } & \multicolumn{2}{|c|}{$95 \% \mathrm{Cl}$} & \multirow[b]{2}{*}{$P$-value } \\
\hline & & & Lower & Upper & \\
\hline \multicolumn{6}{|l|}{ os } \\
\hline \multicolumn{6}{|l|}{ LFFS } \\
\hline $\begin{array}{l}\text { CD68 + (low/high) } \\
\text { CD163 + (low/high) } \\
\text { CD11b }+ \text { (low/high) } \\
\text { Grade (G1/2/G3) } \\
\text { N-stage (NO-1/N2a-b/N2c-N3) } \\
\text { T-stage (T1-2/T3-4) } \\
\text { Tumour localisation } \\
\text { Age (<61/ } \geqslant 61) \\
\text { Sex (male/female) }\end{array}$ & $\begin{array}{l}0.006 \\
0.007 \\
0.275 \\
0.977 \\
0.247 \\
0.370 \\
0.581 \\
0.864 \\
0.460\end{array}$ & $\begin{array}{l}1.466 \\
1.778 \\
1.187 \\
0.681 \\
1.339 \\
0.614 \\
0.685 \\
1.021 \\
0.771\end{array}$ & $\begin{array}{l}0.798 \\
1.038 \\
0.674 \\
0.333 \\
0.869 \\
0.263 \\
0.378 \\
0.577 \\
0.362\end{array}$ & $\begin{array}{l}2.693 \\
3.047 \\
2.093 \\
1.394 \\
2.064 \\
1.429 \\
1.243 \\
1.808 \\
1.643\end{array}$ & $\begin{array}{l}0.217 \\
0.036 \\
0.553 \\
0.293 \\
0.185 \\
0.257 \\
0.213 \\
0.942 \\
0.501\end{array}$ \\
\hline \multicolumn{6}{|l|}{ DMFS } \\
\hline $\begin{array}{l}\text { CD68 + (low/high) } \\
\text { CD163 + (low/high) } \\
\text { CD11b + (low/high) } \\
\text { Grade (G1/2/G3) } \\
\text { N-stage (NO-1/N2a-b/N2c-N3) } \\
\text { T-stage (T1-2/T3-4) } \\
\text { Tumour localisation } \\
\text { Age (<61/ } \geqslant 61) \\
\text { Sex (male/female) }\end{array}$ & $\begin{array}{l}0.011 \\
0.010 \\
0.343 \\
0.984 \\
0.245 \\
0.224 \\
0.856 \\
0.753 \\
0.696\end{array}$ & $\begin{array}{l}1.300 \\
1.807 \\
1.194 \\
0.694 \\
1.390 \\
0.535 \\
0.924 \\
1.184 \\
0.842\end{array}$ & $\begin{array}{l}0.678 \\
1.032 \\
0.656 \\
0.329 \\
0.879 \\
0.226 \\
0.506 \\
0.648 \\
0.387\end{array}$ & $\begin{array}{l}2.492 \\
3.162 \\
2.173 \\
1.465 \\
2.198 \\
1.266 \\
1.686 \\
2.165 \\
1.833\end{array}$ & $\begin{array}{l}0.430 \\
0.038 \\
0.562 \\
0.338 \\
0.159 \\
0.155 \\
0.796 \\
0.583 \\
0.665\end{array}$ \\
\hline
\end{tabular}

the different tumour compartments in HNSCC. Notably, our results are in line with previous reports demonstrating a correlation between high stromal TAMs expression and worse cancer-specific and OS in patients with other tumours, such as breast and lung cancer and melanoma (Jensen et al, 2009; Chung et al, 2012; Medrek et al, 2012).

HPV16-positivity was not associated with more favourable prognosis in our series, which is inconsistent with studies showing better survival in HPV-positive patients following CRT (Lassen et al, 2009; Ang et al, 2010). We believe that this discrepancy is possibly due to the low number of patients with oropharyngeal cancer and the high percentage of older patients in our cohort. Interestingly, high expression of CD163 + TAMs was associated with worse clinical outcome only in HPV16-negative patients in our study. The prognostic impact of TAMs with regard to HPV status remains unclear. A recent work demonstrated CD68+ TAMs colocalisation with the programmed cell death-1 ligand in HPV-positive HNSCC that likely suppress anti-tumour T-cell functions (Lyford-Pike et al, 2013). Additional work is needed to elucidate the correlation of TAMs and HPV. 
Preclinical studies have suggested recruitment of TAMs, including $\mathrm{CD} 11 \mathrm{~b}+$ myeloid cells, a member of the integrin family, as a resistance mechanism to RT (Kuonen et al, 2012; Fokas et al, 2012a; Martin, 2013). Indeed, several groups have shown that ionising radiation can, via vascular damage and induction of hypoxia, lead to the upregulation of hypoxia inducible factor 1 ,
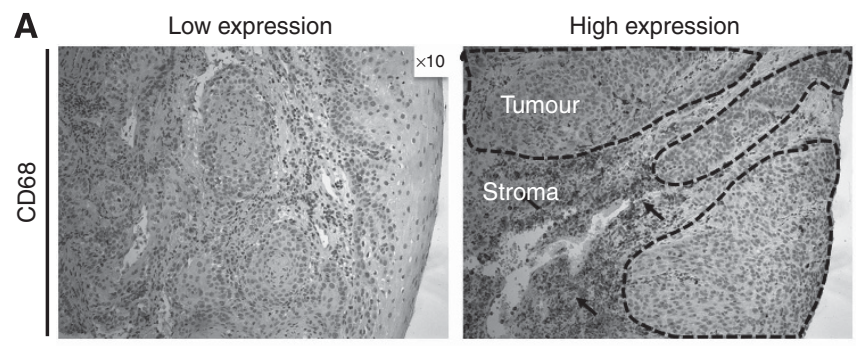

B

Low expression
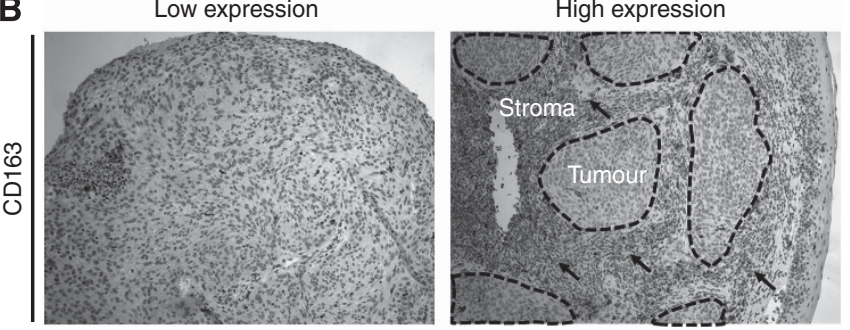

Figure 2. Examples of tumour samples with low and high stromal (A) CD68 and (B) CD163 expression. Areas of interest are depicted as dotted lines (tumor) or arrows (stroma), respectively. Magnification, $\times 10$. activation of cytokine signalling and recruitment of TAMs that result in restoration of vasculature, immunosuppression and tumour progression (Milas, 1990; Moeller et al, 2004; Baeten et al, 2006; Ahn and Brown, 2008; Chen et al, 2009; Ahn et al, 2010; Kioi et al, 2010; Kuonen et al, 2012). Milas (1990) showed that high TAMs expression in tumours enhanced tumour regrowth in pre-irradiated tumour beds. In a preclinical work, CD11b + cell density after 10 daily fractions of $1.84-2$ Gy correlated with the TCD50 (dose to cure $50 \%$ of the tumours ) after 30 fractions, suggesting that $\mathrm{CD} 11 \mathrm{~b}+$ cells may affect local tumour control after fractionated irradiation (Zaleska et al, 2011). In a recent study, irradiation-mediated activation of the v-abl Abelson murine leukaemia viral oncogene homologue 1 kinase upregulated the macrophage colony-stimulating factor 1 (CSF1). The latter resulted in increased recruitment of CSF1R-expressing CD11b + myeloid cells and TAMs that promoted tumour regrowth following RT in a prostate cancer model, whereas a CSF1R inhibitor enhanced response to radiation (Xu et al, 2013). Kioi et al (2010) observed increased intratumoral infiltration by $\mathrm{CD} 11 \mathrm{~b}+$ cells in preclinical models and patients with glioblastoma that promoted recurrence via vasculogenesis after RT. Irradiation of mouse mammary tumours increased influx of $\mathrm{CD} 11 \mathrm{~b}+$ cells that, via expression of matrix metalloproteinase-9, led to vascular restoration, contributing to tumour regrowth (Ahn and Brown, 2008; Ahn et al, 2010). In a similar fashion, Jain and colleagues have found increased CD11b + cell counts in irradiated tumours (Kozin et al, 2010). Targeting CD11b + cells either by a monoclonal antibody or depletion of the bone marrow compartment improved RT response and prevented recurrence, whereas infusion of CD11b + myeloid cells enhanced tumour regrowth after local radiation

A
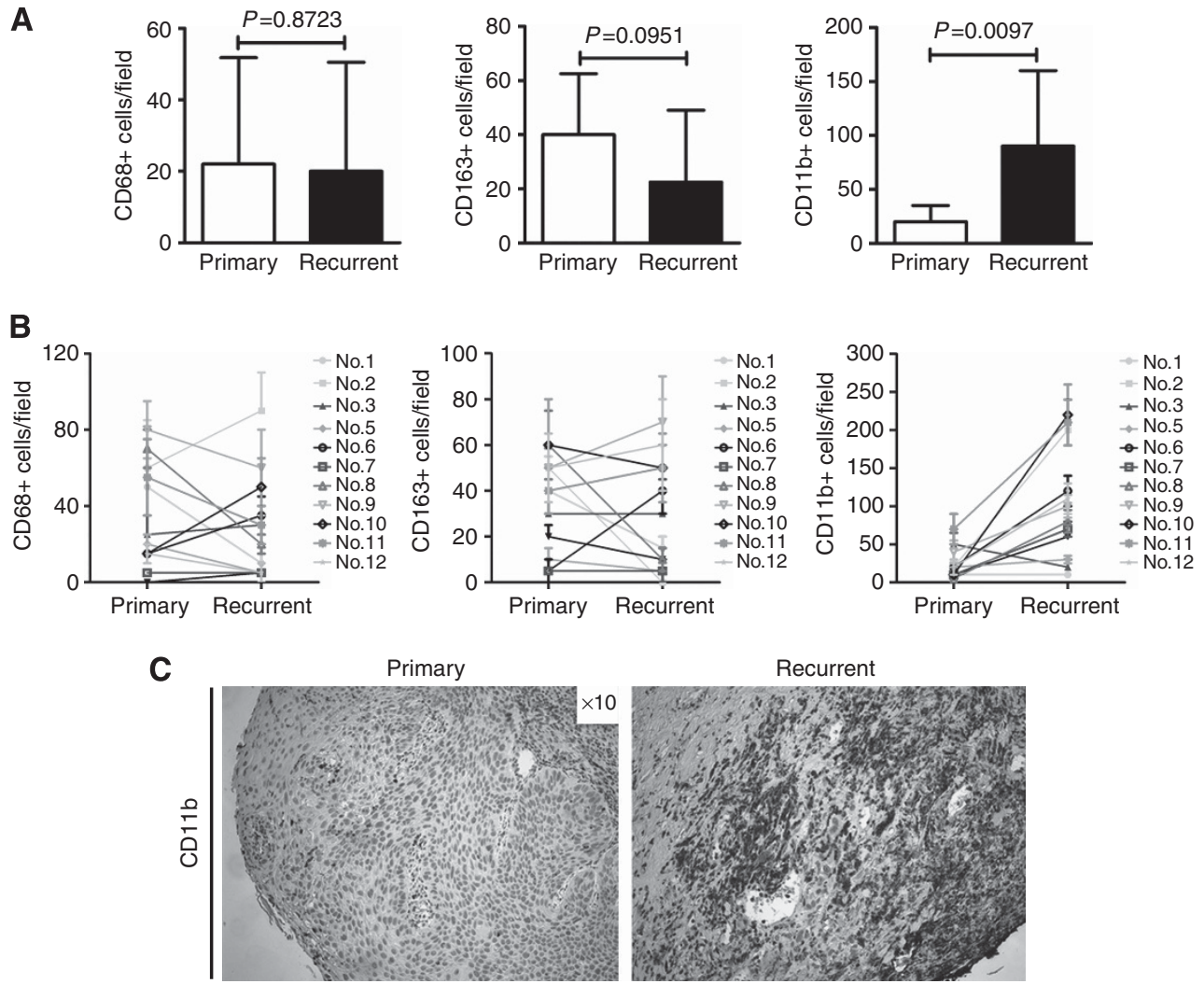

Figure 3. Analysis of CD68, CD163 and CD11b cell number in samples from $n=12$ primary tumours and their matched local recurrence. (A) We did not observe a difference in CD68 + or CD163 + cell influx in the recurrent samples compared with primary tumours. In contrast, there was a significant increase $(P=0.0097)$ in $C D 11 b+$ cell infiltration in recurrent tumours compared with their matched primary tumour samples. (B) Cell number in each of the 12 patients (No.1-12) is shown as indicated. Columns/points, median; bars, s.d. (C) Example of CD11b + expression in primary tumour (left) and its matched recurrence sample (right). Magnification, $\times 10$. 
(Ahn et al, 2010; Kioi et al, 2010; Kozin et al, 2010). The above data indicate that $\mathrm{CD} 11 \mathrm{~b}+$ myeloid cells can facilitate tumour recurrence following $\mathrm{RT}$.

For these reasons, we examined TAMs, including CD11b + cells, in $n=12$ available samples of early local recurrence and their matched primary tumours. We did not find a significant difference in either $\mathrm{CD} 68+$ or $\mathrm{CD} 163+$ cell infiltration between the recurrences and their matched primary tumour samples. In contrast, examination of the recurrence samples demonstrated a significant increase in the number of CD11b + cells that occurred in 10 out of the 12 patients compared with their matched primary samples. Vascular density of the early recurrent tumours was significantly lower compared with their matched primary samples in our series. Local recurrences in all 12 patients occurred in the high radiation dose area ( $\geqslant 70 \mathrm{~Gy}$ ), the common pattern of failure in HNSCC after RT (Daly et al, 2011; Gupta et al, 2011).

Our data show that $\mathrm{CD} 11 \mathrm{~b}+$ myeloid cells can be associated with tumour recurrences following CRT and raise important questions. First, in the clinical setting where daily fractionation doses of 1.4-2 Gy are used, it remains unclear whether these cells infiltrate the tumour already at an early stage during and/or following CRT, as it has been demonstrated for high single radiation doses (15-20 Gy) in preclinical studies (Ahn and Brown, 2008; Ahn et al, 2010; Kioi et al, 2010; Kozin et al, 2010), or whether CD11b + cell influx increases in parallel to the growth of the recurrent tumor. Similarly to our present findings in HNSCC, Brown and colleagues also found higher levels of CD11b + cells in recurrent glioblastomas compared with their matched baseline primary tumours (Kioi et al, 2010), but additional clinical reports are lacking. Hence, it will be interesting to compare the expression of myeloid cells between primary tumours and matched recurrences also in other tumour histologies to see whether this phenomenon occurs in the wider setting after RT/CRT. Second, although the mechanism remains under investigation, $\mathrm{CD} 11 \mathrm{~b}+$ cells can help restore tumour vasculature after large single irradiation doses (Ahn et al, 2010; Kioi et al, 2010; Kozin et al, 2010; Kuonen et al, 2012). Interestingly, in our series, vascular density was significantly lower in recurrent tumours compared with their matched primary samples. Thus, $\mathrm{CD} 11 \mathrm{~b}$ could have contributed to the growth of tumour recurrence via a mechanism other than restoration of vasculature, such as immune evasion. Third, as expected for recurrent tumours previously treated with CRT, $\mathrm{H} \& \mathrm{E}$ analysis of the recurrence specimens revealed increased fibrosis but whether fibrotic tissue could stimulate (or be associated with) CD11b + cell recruitment in tumour recurrences remains largely unexplored. Preclinical studies in non-malignant fibrotic diseases, such as pulmonary and cardiac fibrosis, have reported expression of CD11b + cells (Osterholzer et al, 2012; Wu et al, 2014). Fourth, patients in our study were treated with cisplatin/5-FU-based CRT, and hence we cannot exclude that chemotherapy also fostered myeloid cell recruitment in recurrent tumours. Indeed, there is compelling evidence that chemotherapy drugs, including cisplatin and 5-FU, can result in recruitment of myeloid cells to mediate tumour resistance to treatment (DeNardo et al, 2011; Nakasone et al, 2012; Bruchard et al, 2013; De Palma and Lewis, 2013). Fifth, the precise origin of these cells in patients with tumour recurrences remains largely unexplored. Importantly, in the present work, the expression of $\mathrm{CD} 11 \mathrm{~b}+$ cells in the recurrent samples differed from CD68 + and $\mathrm{CD} 163+$. Thus, CD11b + cells might reflect a different population than $\mathrm{CD} 68+$ and $\mathrm{CD} 163+$ cells in patients with HNSCC recurrence. Indeed, there are several $\mathrm{CD} 11 \mathrm{~b}+$ cell subgroups characterised by different myeloid origin according to myeloidderived suppressor cell markers, such as CD14, CD33 and human leukocyte antigen D-related (Gabrilovich and Nagaraj, 2009), which could also explain the lack of prognostic value for CD11b + cells in primary tumours.
Our study has limitations. First, although patients were treated and followed up prospectively, the retrospective analysis of TAMs cannot exclude potential selection bias. Second, despite the relatively long median follow-up of 40 months, a longer followup is needed. Third, our findings on CD11b + cells were obtained from a small number of recurrent tumours $(n=12)$ and hence need validation in larger cohort.

Taken together, high primary tumour CD163 + TAMs expression was associated with worse outcome in patients with HNSCC following definitive CRT. Early local recurrences showed increased infiltration by $\mathrm{CD} 11 \mathrm{~b}+$ cells. These data highlight TAMs as potential biomarkers for risk stratification and hence patients may benefit from novel agents that target TAMs in combination with RT/CRT.

\section{ACKNOWLEDGEMENTS}

The authors gratefully acknowledge the excellent technical assistance of Yvonne Michel, Senckenberg Institute of Pathology, Goethe University, Frankfurt am Main.

\section{REFERENCES}

Ahn GO, Brown JM (2008) Matrix metalloproteinase-9 is required for tumor vasculogenesis but not for angiogenesis: role of bone marrow-derived myelomonocytic cells. Cancer Cell 13(3): 193-205.

Ahn GO, Tseng D, Liao CH, Dorie MJ, Czechowicz A, Brown JM (2010) Inhibition of Mac-1 (CD11b/CD18) enhances tumor response to radiation by reducing myeloid cell recruitment. Proc Natl Acad Sci USA 107(18): 8363-8368.

Ambarus CA, Krausz S, van Eijk M, Hamann J, Radstake TR, Reedquist KA, Tak PP, Baeten DL (2012) Systematic validation of specific phenotypic markers for in vitro polarised human macrophages. J Immunol Methods 375(1-2): 196-206.

Ang KK, Harris J, Wheeler R, Weber R, Rosenthal DI, Nguyen-Tan PF, Westra WH, Chung CH, Jordan RC, Lu C, Kim H, Axelrod R, Silverman CC, Redmond KP, Gillison ML (2010) Human papillomavirus and survival of patients with oropharyngeal cancer. N Engl J Med 363(1): 24-35.

Argiris A, Karamouzis MV, Raben D, Ferris RL (2008) Head and neck cancer. Lancet 371(9625): 1695-1709.

Baeten CI, Castermans K, Lammering G, Hillen F, Wouters BG, Hillen HF, Griffioen AW, Baeten CG (2006) Effects of radiotherapy and

chemotherapy on angiogenesis and leukocyte infiltration in rectal cancer. Int J Radiat Oncol Biol Phys 66(4): 1219-1227.

Balermpas P, Michel Y, Wagenblast J, Seitz O, Weiss C, Rodel F, Rodel C, Fokas E (2014) Tumour-infiltrating lymphocytes predict response to definitive chemoradiotherapy in head and neck cancer. Br J Cancer 110(2): 501-509.

Baumgarten P, Harter PN, Tonjes M, Capper D, Blank AE, Sahm F, von Deimling A, Kolluru V, Schwamb B, Rabenhorst U, Starzetz T, Kogel D, Rieker RJ, Plate KH, Ohgaki H, Radlwimmer B, Zornig M, Mittelbronn M (2014) Loss of FUBP1 expression in gliomas predicts FUBP1 mutation and is associated with oligodendroglial differentiation IDH1 mutation and 1p/19q loss of heterozygosity. Neuropathol Appl Neurobiol 40(2): 205-216.

Bhardwaj N (2007) Harnessing the immune system to treat cancer. J Clin Invest 117(5): 1130-1136.

Bruchard M, Mignot G, Derangere V, Chalmin F, Chevriaux A, Vegran F, Boireau W, Simon B, Ryffel B, Connat JL, Kanellopoulos J, Martin F, Rebe C, Apetoh L, Ghiringhelli F (2013) Chemotherapy-triggered cathepsin B release in myeloid-derived suppressor cells activates the Nlrp3 inflammasome and promotes tumor growth. Nat Med 19(1): 57-64.

Budach V, Stuschke M, Budach W, Baumann M, Geismar D, Grabenbauer G, Lammert I, Jahnke K, Stueben G, Herrmann T, Bamberg M, Wust P, Hinkelbein W, Wernecke KD (2005) Hyperfractionated accelerated chemoradiation with concurrent fluorouracil-mitomycin is more effective than dose-escalated hyperfractionated accelerated radiation therapy alone in locally advanced head and neck cancer: final results of the radiotherapy 
cooperative clinical trials group of the German Cancer Society 95-06 Prospective Randomized Trial. J Clin Oncol 23(6): 1125-1135.

Chaturvedi AK, Engels EA, Pfeiffer RM, Hernandez BY, Xiao W, Kim E, Jiang B, Goodman MT, Sibug-Saber M, Cozen W, Liu L, Lynch CF, Wentzensen N, Jordan RC, Altekruse S, Anderson WF, Rosenberg PS, Gillison ML (2011) Human papillomavirus and rising oropharyngeal cancer incidence in the United States. J Clin Oncol 29(32): 4294-4301.

Chen FH, Chiang CS, Wang CC, Tsai CS, Jung SM, Lee CC, McBride WH, Hong JH (2009) Radiotherapy decreases vascular density and causes hypoxia with macrophage aggregation in TRAMP-C1 prostate tumors. Clin Cancer Res 15(5): 1721-1729.

Chung FT, Lee KY, Wang CW, Heh CC, Chan YF, Chen HW, Kuo CH, Feng PH, Lin TY, Wang CH, Chou CL, Chen HC, Lin SM, Kuo HP (2012) Tumor-associated macrophages correlate with response to epidermal growth factor receptor-tyrosine kinase inhibitors in advanced non-small cell lung cancer. Int J Cancer 131(3): E227-E235.

Daly ME, Le QT, Kozak MM, Maxim PG, Murphy JD, Hsu A, Loo Jr BW, Kaplan MJ, Fischbein NJ, Chang DT (2011) Intensity-modulated radiotherapy for oral cavity squamous cell carcinoma: patterns of failure and predictors of local control. Int J Radiat Oncol Biol Phys 80(5): 1412-1422.

De Palma M, Lewis CE (2013) Macrophage regulation of tumor responses to anticancer therapies. Cancer Cell 23(3): 277-286.

DeNardo DG, Brennan DJ, Rexhepaj E, Ruffell B, Shiao SL, Madden SF, Gallagher WM, Wadhwani N, Keil SD, Junaid SA, Rugo HS, Hwang ES, Jirstrom K, West BL, Coussens LM (2011) Leukocyte complexity predicts breast cancer survival and functionally regulates response to chemotherapy. Cancer Discov 1(1): 54-67.

Fokas E, McKenna WG, Muschel RJ (2012a) The impact of tumor microenvironment on cancer treatment and its modulation by direct and indirect antivascular strategies. Cancer Metastasis Rev 31(3-4): 823-842.

Fokas E, Prevo R, Pollard JR, Reaper PM, Charlton PA, Cornelissen B, Vallis KA, Hammond EM, Olcina MM, Gillies McKenna W, Muschel RJ, Brunner TB (2012b) Targeting ATR in vivo using the novel inhibitor VE-822 results in selective sensitization of pancreatic tumors to radiation. Cell Death Dis 3: e441.

Fujii N, Shomori K, Shiomi T, Nakabayashi M, Takeda C, Ryoke K, Ito H (2012) Cancer-associated fibroblasts and CD163-positive macrophages in oral squamous cell carcinoma: their clinicopathological and prognostic significance. J Oral Pathol Med 41(6): 444-451.

Gabrilovich DI, Nagaraj S (2009) Myeloid-derived suppressor cells as regulators of the immune system. Nat Rev Immunol 9(3): 162-174.

Gupta T, Jain S, Agarwal JP, Ghosh-Laskar S, Phurailatpam R, Pai-Shetty R, Dinshaw KA (2011) Prospective assessment of patterns of failure after high-precision definitive (chemo)radiation in head-and-neck squamous cell carcinoma. Int J Radiat Oncol Biol Phys 80(2): 522-531.

Ibe S, Qin Z, Schuler T, Preiss S, Blankenstein T (2001) Tumor rejection by disturbing tumor stroma cell interactions. J Exp Med 194(11): $1549-1559$

Jensen TO, Schmidt H, Moller HJ, Hoyer M, Maniecki MB, Sjoegren P, Christensen IJ, Steiniche T (2009) Macrophage markers in serum and tumor have prognostic impact in American Joint Committee on Cancer stage I/II melanoma. J Clin Oncol 27(20): 3330-3337.

Kerrebijn JD, Balm AJ, Knegt PP, Meeuwis CA, Drexhage HA (1994) Macrophage and dendritic cell infiltration in head and neck squamous-cell carcinoma; an immunohistochemical study. Cancer Immunol Immunother 38(1): 31-37.

Kioi M, Vogel H, Schultz G, Hoffman RM, Harsh GR, Brown JM (2010) Inhibition of vasculogenesis, but not angiogenesis, prevents the recurrence of glioblastoma after irradiation in mice. J Clin Invest 120(3): 694-705.

Kozin SV, Kamoun WS, Huang Y, Dawson MR, Jain RK, Duda DG (2010) Recruitment of myeloid but not endothelial precursor cells facilitates tumor regrowth after local irradiation. Cancer Res 70(14): 5679-5685.

Kuonen F, Secondini C, Ruegg C (2012) Molecular pathways: emerging pathways mediating growth, invasion, and metastasis of tumors progressing in an irradiated microenvironment. Clin Cancer Res 18(19): 5196-5202.

Lassen P, Eriksen JG, Hamilton-Dutoit S, Tramm T, Alsner J, Overgaard J (2009) Effect of HPV-associated p16INK4A expression on response to radiotherapy and survival in squamous cell carcinoma of the head and neck. J Clin Oncol 27(12): 1992-1998.
Lau SK, Chu PG, Weiss LM (2004) CD163: a specific marker of macrophages in paraffin-embedded tissue samples. Am J Clin Pathol 122(5): 794-801.

Lee CH, Espinosa I, Vrijaldenhoven S, Subramanian S, Montgomery KD, Zhu S, Marinelli RJ, Peterse JL, Poulin N, Nielsen TO, West RB, Gilks CB, van de Rijn M (2008) Prognostic significance of macrophage infiltration in leiomyosarcomas. Clin Cancer Res 14(5): 1423-1430.

Li C, Shintani S, Terakado N, Nakashiro K, Hamakawa H (2002) Infiltration of tumor-associated macrophages in human oral squamous cell carcinoma. Oncol Rep 9(6): 1219-1223.

Lima L, Oliveira D, Tavares A, Amaro T, Cruz R, Oliveira MJ, Ferreira JA, Santos L (2013) The predominance of M2-polarised macrophages in the stroma of low-hypoxic bladder tumors is associated with BCG immunotherapy failure. Urol Oncol 32(4): 449-457.

Luo Y, Zhou H, Krueger J, Kaplan C, Lee SH, Dolman C, Markowitz D, Wu W, Liu C, Reisfeld RA, Xiang R (2006) Targeting tumor-associated macrophages as a novel strategy against breast cancer. J Clin Invest 116(8): 2132-2141.

Lyford-Pike S, Peng S, Young GD, Taube JM, Westra WH, Akpeng B, Bruno TC, Richmon JD, Wang H, Bishop JA, Chen L, Drake CG, Topalian SL, Pardoll DM, Pai SI (2013) Evidence for a role of the PD-1:PD-L1 pathway in immune resistance of HPV-associated head and neck squamous cell carcinoma. Cancer Res 73(6): 1733-1741.

Marcus B, Arenberg D, Lee J, Kleer C, Chepeha DB, Schmalbach CE, Islam M, Paul S, Pan Q, Hanash S, Kuick R, Merajver SD, Teknos TN (2004) Prognostic factors in oral cavity and oropharyngeal squamous cell carcinoma. Cancer 101(12): 2779-2787.

Martin BJ (2013) Inhibiting vasculogenesis after radiation: a new paradigm to improve local control by radiotherapy. Semin Radiat Oncol 23(4): 281-287.

Medrek C, Ponten F, Jirstrom K, Leandersson K (2012) The presence of tumour associated macrophages in tumor stroma as a prognostic marker for breast cancer patients. BMC Cancer 12: 306.

Milas L (1990) Tumor bed effect in murine tumors: relationship to tumor take and tumor macrophage content. Radiat Res 123(2): 232-236.

Moeller BJ, Cao Y, Li CY, Dewhirst MW (2004) Radiation activates HIF-1 to regulate vascular radiosensitivity in tumors: role of reoxygenation, free radicals, and stress granules. Cancer Cell 5(5): 429-441.

Mori K, Hiroi M, Shimada J, Ohmori Y (2011) Infiltration of m2 tumorassociated macrophages in oral squamous cell carcinoma correlates with tumor malignancy. Cancers (Basel) 3(4): 3726-3739.

Nakasone ES, Askautrud HA, Kees T, Park JH, Plaks V, Ewald AJ, Fein M, Rasch MG, Tan YX, Qiu J, Park J, Sinha P, Bissell MJ, Frengen E, Werb Z, Egeblad M (2012) Imaging tumor-stroma interactions during chemotherapy reveals contributions of the microenvironment to resistance. Cancer Cell 21(4): 488-503.

Osterholzer JJ, Christensen PJ, Lama V, Horowitz JC, Hattori N, Subbotina N, Cunningham A, Lin Y, Murdock BJ, Morey RE, Olszewski MA, Lawrence DA, Simon RH, Sisson TH (2012) PAI-1 promotes the accumulation of exudate macrophages and worsens pulmonary fibrosis following type II alveolar epithelial cell injury. J Pathol 228(2): 170-180.

Pyonteck SM, Akkari L, Schuhmacher AJ, Bowman RL, Sevenich L, Quail DF, Olson OC, Quick ML, Huse JT, Teijeiro V, Setty M, Leslie CS, Oei Y, Pedraza A, Zhang J, Brennan CW, Sutton JC, Holland EC, Daniel D, Joyce JA (2013) CSF-1R inhibition alters macrophage polarization and blocks glioma progression. Nat Med 19(10): 1264-1272.

Qian BZ, Pollard JW (2010) Macrophage diversity enhances tumor progression and metastasis. Cell 141(1): 39-51.

Russell SM, Angell T, Lechner MG, Liebertz DJ, Correa AJ, Sinha UK, Kokot N, Epstein AL (2013) Immune cell infiltration patterns and survival in head and neck squamous cell carcinoma. Head Neck Oncol 5(3): 24.

Steidl C, Lee T, Shah SP, Farinha P, Han G, Nayar T, Delaney A, Jones SJ, Iqbal J, Weisenburger DD, Bast MA, Rosenwald A, Muller-Hermelink HK, Rimsza LM, Campo E, Delabie J, Braziel RM, Cook JR, Tubbs RR, Jaffe ES, Lenz G, Connors JM, Staudt LM, Chan WC, Gascoyne RD (2010) Tumour-associated macrophages and survival in classic Hodgkin's lymphoma. N Engl J Med 362(10): 875-885.

Tan KL, Scott DW, Hong F, Kahl BS, Fisher RI, Bartlett NL, Advani RH, Buckstein R, Rimsza LM, Connors JM, Steidl C, Gordon LI, Horning SJ, 
Gascoyne RD (2012) Tumor-associated macrophages predict inferior outcomes in classic Hodgkin lymphoma: a correlative study from the E2496 Intergroup trial. Blood 120(16): 3280-3287.

Wu Y, Li Y, Zhang C, A X, Wang Y, Cui W, Li H, Du J (2014) S100a8/a9 Released by CD11b + Gr1 + Neutrophils Activates Cardiac Fibroblasts to Initiate Angiotensin II-Induced Cardiac Inflammation and Injury. Hypertension 63(6): 1241-1250.

Xu J, Escamilla J, Mok S, David J, Priceman S, West B, Bollag G, McBride W, Wu L (2013) CSF1R signaling blockade stanches tumor-infiltrating myeloid cells and improves the efficacy of radiotherapy in prostate cancer. Cancer Res 73(9): 2782-2794.
Zaleska K, Bruechner K, Baumann M, Zips D, Yaromina A (2011) Tumourinfiltrating $\mathrm{CD} 11 \mathrm{~b}+$ myelomonocytes and response to fractionated irradiation of human squamous cell carcinoma (hSCC) xenografts. Radiother Oncol 101(1): 80-85.

This work is published under the standard license to publish agreement. After 12 months the work will become freely available and the license terms will switch to a Creative Commons AttributionNonCommercial-Share Alike 3.0 Unported License.

Supplementary Information accompanies this paper on British Journal of Cancer website (http://www.nature.com/bjc) 